Research Paper:

\title{
Presenting a Causal Model for Depression in Adolescents Based on the Relationship Between Parenting Styles Through the Mediating Role of Parent-Adolescence Conflict
}

\author{
Masumeh Besharatypoor $^{1^{*}} \mathbf{9}$, Amin Khalidinia $^{2}$
}

1. Department of Psychology, Payame Noor University, Tehran, Iran

2. Department of Psychology, Ahvaz Branch, Islamic Azad University, Ahvaz, Iran.

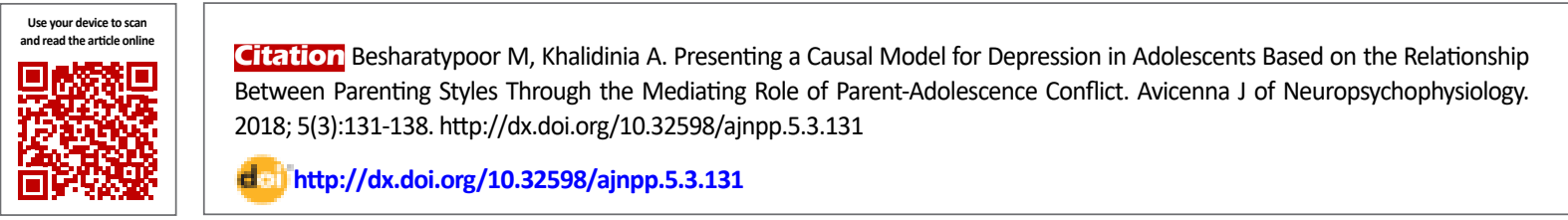

\section{(ㄷ) 00}

Article Info:

Received: 03 Mar 2018

Accepted: 26 Jun 2018

Available Online: 01 Aug 2018

Keywords:

Depression, adolescents, parenting styles, Conflict, parents - Adolescents

\section{ABSTRACT}

Introduction: Studies in the recent two decades have shown that the quality of parental and adolescent communication has a major impact on the development of risk behaviors in adolescents.

Objectives: The purpose of this study was to investigate the causal model for depression in adolescents, based on the parenting styles through the mediating role of the parent-adolescence conflict.

Materials and Methods: The sample consisted of 150 male high school students in the first grade selected by a multistage random sampling method. In this research, the subjects completed the Children's Depression Inventory short form (CDI-S), Baumrind Parenting Styles Questionnaire (BPSQ), and Parent-Adolescent Conflict (PAC) scale. The proposed model was evaluated using structural equation modeling method. Indirect relationships were tested by the Bootstrap method.

Results: The results of this study showed that the proposed model had an acceptable fit to the data, and all paths showed a significant relationship between parenting style (mediated by the parent-adolescent conflict) and for depression in young people, except for the authoritative parenting style. The results of several indirect paths showed that a significant relationship between permissive and authoritarian parenting styles (through parent-adolescent conflict) and depression in adolescents.

Conclusion: The conflict between parents and adolescents can have an impact on children's psychological health. Therefore, solving family problems and providing an appropriate environment at home leads to physical and mental health in adolescents and also improves the proper functioning of the school and community.

* Corresponding Author:

Masumeh Besharatypoor, PhD.

Address: Department of Psychology, Payame Noor University, Tehran, Iran.

Tel: +98 (937) 0153615

E-mail: mbesharatypoor@yahoo.com 


\section{Introduction}

epression is currently a common mental illness, which is growing in many countries around the world. Today, according to extent of its outbreak, depression is called as "mental cold" [1]. Depression disorders have always been the most common psychiatric disorder among adolescents and the suicide outbreak is increased from $49 \%$ to $64 \%$ during adolescence [2]. Depression in children and adolescents due to the clinical (3\%) and non-clinical (35\%) causes and also the impairment of various social, educational, professional and other functions should be widely considered. Many psychosocial factors leading to adolescent depression and different theories have been introduced as determinants affecting depression [3].

Several theories and investigations have been targeted behavioral and psychological problems in children and adolescents, which have tried to find the mechanisms and factors to cause behavioral and psychological harm in children and adolescents. Adolescents' behavioral problems lead to their failure to achieve their goals [4]. Studies on the role of the family in the development of behavioral and psychological problems of adolescents have shown four family backgrounds, including family conflict, family conflict, family neglect and family deviance to affect the mental and behavioral health of adolescents and ultimately their performance [4].

Children's problem can not be addressed, regardless of the attitudes, behaviors, and parenting factors. Although psychologists and theorists emphasize the role of parents and parenting styles, little research has been carried out on child development and psychopathology [5]. The researchers have examined the relationship between the parenting style and the psychological and behavioral health of adolescents, which, based on the studies of the Western societies, it has shown that authoritarian parents had less psychological and behavioral problems. The young people with tyrant parents have an increased depression, anger, suicidal thoughts, and other emotional problems. Gender also moderates the influence of authoritarian parents on behavioral problems, which is more obvious in boys than girls [6].

Authoritative parenting has been linked to the best adolescent emotional and behavioral outcomes than other parenting styles. It is expected that having an authoritative parent is a protective factor for girls' selfadaptation, however in boys; a high level of abuse in the school has been reported [7]. Branje et al. found that the quality of mother and child communication was associated with a high level of depression symptoms in boys and girls among Netherlands teens. The poor quality of the relationship between father and child predicted depression symptoms only in boys. Furthermore, signs of depression predicted poor communication quality between parents and children [8].

Similarly, parent-child conflict was found associated with an increase in non-communicative symptoms and depression [9]. Parent-child conflict is inevitable, but the relationships characterized by high rates of conflict have consistently contributed to the development of socioemotional dysfunction among school-aged children through adolescence [10]. Parent-child conflict can be defined as an aspect of the parent-child relationship that is characterized by discordant or acrimonious interactions, during which both the parent and child display negative behaviors and affect [11]. Trentacosta et al. showed a decline in the mother-son conflict in the majority of dyads in a risk sample from middle childhood to early adolescence [12].

The relationship between parent-child conflicts and psychological health, verbal and physical aggression in parents is related to their psychological health [13]. Klahr et al. stated a positive and significant relationship between parent-child conflict and the child's behavioral problems, such as conduct disorder [14]. In recent years, the effect of parental behavior and parenting styles and the emotional and behavioral consequences of teens has widely considered and defined. Empirical studies focusing on the relationship between parenting style and behavioral consequences of adolescents are crucial, since the effect of parenting behavior continues during adolescence until adulthood [15].

Therefore, the necessity of this study was to find the relationship between parent-child conflict and the initial involvement of parents and children with internalizing disorders (anxiety and depression) and its impact on social, educational, and occupational affairs to provide an effective person to be helpful for the society. Therefore, the purpose of the current study was to present a causal model for depression in adolescents based on the relationship between parenting styles through the mediating role of parent-adolescence conflict in high school boys.

\section{Materials \& Methods}

The present research was a structural equation-modeling algorithm to examine the relationships between 
research variables as a pattern. The statistical population consisted of all adolescents studying at schools for boys in the Imam Khomeini port in 2017 - 2018. The multi-stage random cluster sampling method was performed. First, among six high schools including firstgrade students, three high schools, and then two high schools were selected randomly. Therefore, by considering classes, the students of each class were selected as the sample. The inclusion criteria were the student's with an age range of 13 - 15 years and the willingness to participate in the study. The exclusion criteria were also unwillingness to participate in the research and the age of under 13 or over 15 years (Figure 1 ).

Informed consent was obtained from each participant and the research was approved by the ethics committee at Payame Noor University of Imam Khomeini port. After sampling based on the inclusion and exclusion criteria, the questionnaires were responded by the subjects. The Children's Depression Inventory short form (CDI-S), the Baumrind Parenting Styles Questionnaire (BPSQ) and the Parent-Adolescent Conflict (PAC) Scale were used to collect data.

\section{The Children's Depression Inventory short form (CDI-S)}

It is a ten-item screening instrument with scores ranging from 0-20 that can be used by health workers at all levels of training and in clinical as well as non-clinical settings to identify children with elevated depressive symptoms comparable with major depression [16]. Rajabi and Attari have demonstrated the validity and/ or reliability of CDI [17]. The CDI has considered more other measures of depressive symptoms due to its widespread use. It has been the most commonly used instrument to assess depression in trials on children since 1984 [17]. In the current research, its Cronbach's alpha coefficient was 0.70 .

\section{The Baumrind Parenting Styles Questionnaire (BPSQ)}

Baumrind developed BPSQ in 1991 to evaluate parenting styles, including permissive, authoritarian or authoritarian styles [18]. Buri et al. reported the test reliability of 0.81 for the permissive style, 0.92 for the authoritarian style, and 0.92 for the authoritarian style. The correlation of -0.5 for the permissive and authoritative parenting styles and -0.52 for the authoritative and authoritarian styles in mothers confirmed its validity [18]. In addition, Moradian et al. reported the reliability $0.79,0.69$, and 0.86 using Cronbach's alpha , for permissive, authoritarian and authoritative styles, respectively [19]. Cronbach's alpha was used to determine the reli- ability of the BPSQ and for the total questionnaire was obtained 0.72 , indicating its acceptable reliability coefficients.

\section{Parent-Adolescent Conflict (PAC) scale}

The conflict dimension of the "Adolescent Family Process" scale [20] measured the frequency of PAC scale. Items were rated on a scale ranging from 1 (never) to 5 (very often). Psychometric Iranian studies have indicated its structure same as the original State-Trait depression Questionnaire (ST-DEP). For each topic during the discussions, adolescents reported the conflict intensity of the discussions related to each topic, using a 5-point scale scored from 1 (very calm) to 5 (very angry). The parent-adolescence conflict was obtained by averaging the adolescents' scores to the items $\alpha=0.73$ [21]. In the current research, a Cronbach's alpha coefficient of 0.78 was obtained.

Before data analysis, the correlations between depression, parenting styles, and parent-adolescent conflict were calculated using Pearson correlation coefficient by SPSS V. 23. Path analysis was then performed with latent variables using AMOS 18.

\section{Results}

A total of 150 adolescents were studied. The minimum and maximum age of participants was 13 and 15 years, respectively. The mean age of subjects was $13.55 \pm 0.56$ years. Table 1 shows the descriptive statistics and correlations of the study variables. The results of the Pearson correlation matrix indicated positive and significant correlations between depression in adolescents, parenting styles, and the parent-adolescence conflict $(P<0.05$; Table 2).

As shown in Table1, the assumed relationship between variables corresponded to the expected paths. In other words, there was a significant relationship between variables. These correlations of insight into relations between research variables provide. Structural Equation Modeling (SEM) was applied to analyze the possible relationships between variables simultaneously. As shown in Table 2, based on the goodness of indicators, the model's fit was not satisfactory, which was increased after elimination of the non - significant fitness paths of the model. Finally, the result showed the goodness of fit of the final model.

Table 3 represents the direct relationship between the variables of the model. Results showed that the per- 
Table 1. Correlation between variables

\begin{tabular}{|c|c|c|c|c|c|c|c|}
\hline Variables & 1 & 2 & 3 & 4 & 5 & 6 & 7 \\
\hline Permissive parenting style & - & - & - & - & - & - & - \\
\hline Authoritarian parenting style & $0.29 * *$ & - & - & - & - & - & - \\
\hline Authoritative parenting style & 0.03 & $-0.16^{*}$ & - & - & - & - & - \\
\hline Parent- adolescence conflict & $0.24 * * *$ & $0.28^{* *}$ & -0.06 & - & - & - & - \\
\hline Mother- adolescence conflict & $0.18^{*}$ & $0.28^{* *}$ & $-0.13^{* * *}$ & $0.83^{* * *}$ & - & - & - \\
\hline Father- adolescence conflict & $0.23^{* * *}$ & $0.20 * *$ & 0.02 & $0.83^{* * *}$ & $0.39 * * *$ & - & - \\
\hline Adolescence Depression & 0.12 & $0.39 * * *$ & $-0.22 * *$ & $0.57 * * *$ & $0.41^{* * *}$ & $0.54 * * *$ & 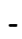 \\
\hline \multicolumn{8}{|l|}{$* * * P<0.001$} \\
\hline \multicolumn{8}{|l|}{$* * P<0.01$} \\
\hline$* P<0.05$ & & & & & & & \\
\hline
\end{tabular}

Table 2. The goodness of fit of the proposed pattern based on the goodness of indicators

\begin{tabular}{cccccccccc}
\hline The Goodness of Fit & $\boldsymbol{\chi}^{2}$ & $\mathbf{d f}$ & $\mathbf{d f} / \boldsymbol{\chi}^{2}$ & $\mathbf{p}$ & $\mathbf{C F I}$ & IFI & TLI & NFI & RMSEA \\
\hline Suggested pattern & 6.14 & 3 & 2.05 & 0.105 & 0.976 & 0.978 & 0.882 & 0.959 & 0.084 \\
Final pattern & 6.16 & 4 & 1.54 & 0.187 & 0.984 & 0.985 & 0.939 & 0.959 & 0.060 \\
\hline
\end{tabular}

RMSEA: Root Mean Square Error of Approximation

AJNPP

missive parenting style was associated positively with parent-adolescence conflict.

The direct relationship between the variables of the model is presented in Table 3 . The results showed that the permissive parenting style was positively associated with parent-adolescence conflict $(\beta=0.25)$. In addition, a significant relationship was found between authoritarian $(\beta=0.26)$ and authoritative $(\beta=0.01)$ styles and parent-adolescence conflict. Parent-adolescence con- flict was positively correlated with depression in adolescents $(\beta=0.73)$.

Therefore, the results showed that the permissive parenting style was negatively correlated with depression in the subjects $(\beta=-0.17)$. Authoritarian parenting style indicated a significant relationship with depression in the participants $(\beta=0.17)$. Moreover, a significant correlation was found between the authoritative parenting style and depression $(\beta=-0.17)$.

Table 3. Structural model: Standardized values (direct relationship)

\begin{tabular}{|c|c|c|c|c|c|c|}
\hline \multirow{2}{*}{ Pathways } & \multicolumn{3}{|c|}{ Proposed Pattern } & \multicolumn{3}{|c|}{ Final Pattern } \\
\hline & $\beta$ & Critical Ratio1 & p & $\beta$ & Critical Ratio & $\mathbf{P}$ \\
\hline Permissive parenting style $\rightarrow$ Parent-adolescence conflict & 0.25 & 2.27 & 0.023 & 0.25 & 2.27 & 0.023 \\
\hline $\begin{array}{l}\text { Authoritarian parenting style } \rightarrow \text { Parent-adolescence } \\
\text { conflict }\end{array}$ & 0.26 & 2.36 & 0.018 & 0.26 & 2.37 & 0.018 \\
\hline $\begin{array}{l}\text { Authoritative parenting style } \rightarrow \text { Parent-adolescence } \\
\text { conflict }\end{array}$ & 0.01 & 0.125 & 0.009 & - & - & - \\
\hline Parent-adolescence conflict $\rightarrow$ Adolescence Depression & 0.73 & 4.50 & 0.0001 & 0.73 & 4.50 & 0.0001 \\
\hline$\rightarrow$ Adolescence Depression Permissive parenting style & $0.17-$ & $2.10-$ & 0.036 & $0.17-$ & $2.10-$ & 0.036 \\
\hline Authoritarian parenting style $\rightarrow$ Adolescence Depression & 0.17 & 2.04 & 0.041 & 0.17 & 2.05 & 0.004 \\
\hline$\rightarrow$ Adolescence Depression Authoritative parenting style & $0.17-$ & $2.50-$ & 0.012 & $0.17-$ & 2.75- & 0.006 \\
\hline
\end{tabular}




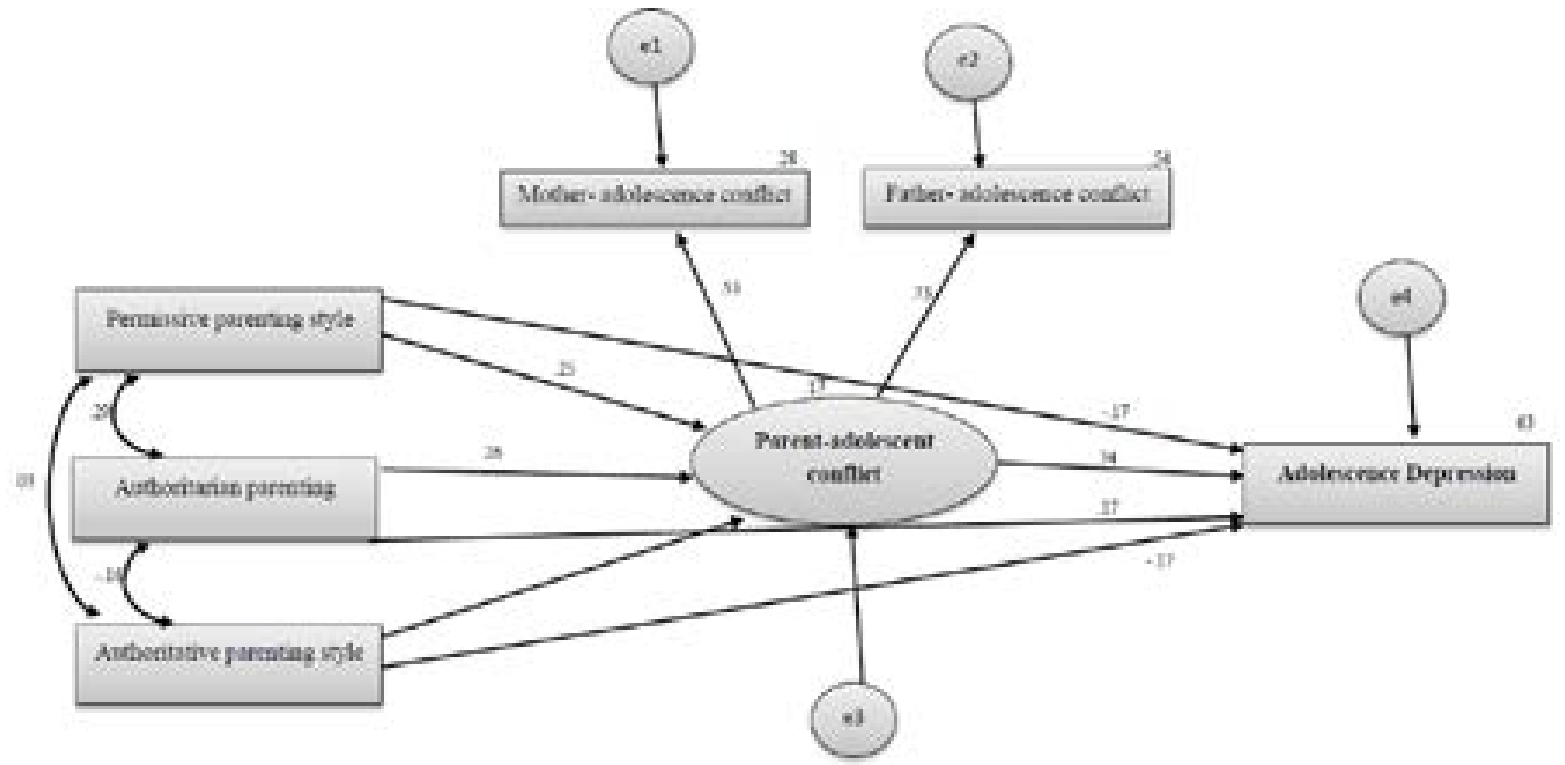

Figure 1. The standard pattern of the paths of the proposed pattern

Table 4. The results of multivariate Bootstrap Analysis

\begin{tabular}{|c|c|c|c|c|c|c|}
\hline Variable & Data & Boot & Bias & SE & Low & High \\
\hline $\begin{array}{c}\text { Permissive parenting style } \rightarrow \text { Parent-adolescence conflict } \rightarrow \text { Adoles- } \\
\text { cence Depression }\end{array}$ & 0.160 & 0.158 & -0.002 & 0.53 & 0.056 & 0.265 \\
\hline $\begin{array}{l}\text { Authoritarian parenting style } \rightarrow \text { Parent-adolescence conflict } \rightarrow \text { Ado- } \\
\text { lescence Depression }\end{array}$ & 0.131 & 0.130 & 0.001 - & 0.037 & 0.060 & 0.212 \\
\hline $\begin{array}{c}\text { Authoritative parenting style } \rightarrow \text { Parent-adolescence conflict } \rightarrow \text { Ado- } \\
\text { lescence Depression }\end{array}$ & -0.062 & $0.052-$ & 0.005 & 0.109 & 0.282 & 0.143 \\
\hline
\end{tabular}

Based on the standard parameter coefficients as well as the corresponding critical ratio values presented in the final model, all direct paths were significant (except for the path of the authoritative parenting style to the parent-adolescence conflict (Table 4).

As shown in Table 4, for the permissive parenting style and depression in adolescents (by the mediating role of parent-adolescent conflict), the lower and upper limit of the confidence interval was 0.056 and 0.265 , respectively. Regarding depression in adolescents and authoritarian parenting style (with the mediating role of parent-adolescent conflict), the lower and upper limits of the confidence interval were 0.062 and 0.212 , respectively. In addition, the confidence level was $95 \%$ and the number of Bootstrap re-samplings was 1000 .

The absence of a zero in 95\% confidence interval indicated the significance of these indirect paths. As seen in the Table 4, for the authoritative parenting style (through the conflict of parent-adolescent) and the depression in adolescents, the lower and upper limits of the confidence interval were -0.2823 and 0.1430 , re- spectively. The presence of a zero in this interval indicated that the indirect route was not significant.

\section{Discussion}

The aim of this study was to investigate the causal model for depression in adolescents, based on parenting styles through the mediating role of parent-adolescence conflicts in the first-grade students of Imam Khomeini port. The model analysis results showed the significance of the indirect path between the permissive parenting styles (with a mediating role of parent-adolescence conflicts) and depressed adolescents. In addition, the authoritarian parenting style (by a mediating role of parent-adolescence conflicts) and depression in adolescents indicated a significant indirect path. However, regarding the relationship between the authoritative parenting style (with a mediating role of parent-adolescence conflicts) and the depression in adolescents, this indirect path was not significant.

In fact, all direct paths (except for the authoritative parenting style with a mediating role of parent-adoles- 
cence conflicts) were significant. This finding is in line with the results of other studies [22-25]. Moreover, previous studies have shown that the authoritative style has the greatest impact on children's emotional growth. Indeed, strong parents treat their children in a kind and intimate manner. These parents not only control their children logically, but also encourage their children to behave fairly and rational. Although these parents respect their children's decisions and reasoning, they insist on their willingness and explain their recommendations [25].

Having authoritative parents is negatively correlated with depression, loneliness, violence, and aggression in children [26]. In fact, most studies are in agreement with the results obtained in this study. Therefore, adolescents living in respectable families consistently show less protective behaviors than adolescents in ineligible families. Parenting styles have shown to be correlated with the risk behaviors related to warmth and intimacy, academic achievement, and psychological adjustment [27]. In a study [28], the perceived credible parenting style by adolescents resulted in higher rates of performance and lower depression. The authoritative parents are responsive, while also setting clear limits for their children. Authoritative parenting styles have positive effects on the early development of children and adolescents. The authoritative parenting style has been introduced as the best-fitted pattern for the prediction of mental health [29].

In western societies, parenting styles have shown as the predictors of parent-adolescent conflict and cohesion. Previous studies have shown that teenagers of authoritative parents have a lower frequency and intensity of conflict and greater cohesion than those with authoritarian parents [30]. In addition, the intensity of the conflict is correlated with the parenting style. In comparison with indulgent parenting styles, teenagers of negligent and authoritarian parents experience greater conflict intensity. Authoritative parents make relatively few demands on young people's behavior, giving them a high degree of freedom to act as they wish.

Authoritarian parents attach great importance to obedience and compliance and also to give and take, less verbally. On the other hand, permissive parents are characterized by a lack of warmth and guidance, while authoritarian parents attach great importance to obedience and conformity and allow less verbal donation. Conflict can be more intense in the permissive parenting style because the teenager is making demands on a parent who otherwise is withdrawn and minimizing of the needs of young people [31]. Adolescents may also be unhappy with the setting broad rules by authoritarian parents without emotional support, which leads to a more intense conflict [32].

Parent-adolescent conflict and hostile relationships in the family result in frustration and antisocial attitudes that ultimately leads to deviant behaviors in adolescents [4]. Therefore, it can be argued that conflict between parents and teenagers can negatively affect the child's psychological health. In addition, solving family problems and providing a healthy environment at home lead to physical and mental health and improves the proper functioning of the school and community [4].

This study was associated with several limitations. First, data were collected by self - report method, which could reduce their reliability. Secondly, the current study was carried out on boys. Therefore the generalization of its results to the girls should be done cautiously. Thirdly, it's the used small sample size could limit the generalizability of the results. Further studies are recommended to be done in the future using a larger sample size to evaluate the generalizability of our results. Finally, no data were collected from the participants (or their parents) in terms of their socio-economic status affecting the developmental depression of the adolescents.

The model analysis results showed a significant indirect path between the permissive parenting styles (with a mediating role of parent-adolescence conflicts) and depressed adolescents. In addition, the authoritarian parenting style (through the mediating role of parentadolescence conflicts) and depression in adolescents indicates the significance of this indirect path. However, regarding the relationship between the authoritative parenting style (with a mediating role of parent-adolescence conflicts) and the depression in adolescents, this indirect path was not significance.

\section{Ethical Considerations}

\section{Compliance with ethical guidelines}

The Ethics Committee of the Payame Noor University approved the research protocol.

\section{Funding}

This research did not receive any specific grant from funding agencies in the public, commercial, or not-forprofit sectors. 


\section{Authors' contributions}

All authors contributed in preparing this article

\section{Conflict of interest}

The authors declared no conflict of interest.

\section{References:}

[1] Ostrov JM, Bishop CM. Preschoolers' aggression and parent-child conflict: A multiinformant and multimethod study. Journal of Experimental Child Psychology. 2008; 99(4):309-22. [DOI:10.1016/j. jecp.2008.01.001] [PMID]

[2] Özmete E, Bayoğlu AS. Parent-young adult conflict: A measurement on frequency and intensity of conflict issues. The Journal of International Social Research. 2009; 2(8):313-22. https://pdfs.semanticscholar.org/429f/e68cfb68154b35c1fc276068dad906e9295c.pdf

[3] Mostafaei MR, Bashirian S. [Comparative survey of depression among chronic disease and healthy adolescences of Hamadan City (Persian)]. Avicenna Journal of Nursing and Midwifery Care. 2012; 20(2):65-71. http://nmj.umsha.ac.ir/article-1-1116-fa.html

[4] Shehni-Yailagh M, Azizimehr A, Maktabi GH. [The causal relationship between covert and overt conflicts and school performance, mediated by parent-child relationship, antisocial behavior and withdrawal/depression among high school students (Persian)]. Biannual Journal of Applied Counseling. 2014; 3(2):1-16. http://jac.scu.ac.ir/ article_10669.htm

[5] McDermott Panetta Sh, Somers CL, Ceresnie AR, Hillman SB, Partridge RT. Maternal and paternal parenting style patterns and adolescent emotional and behavioral outcomes. Marriage \& Family Review. 2014; 50(4):342-59. [DOI:10.1080/01494929.2013.879557]

[6] Muhtadie L, Zhou Q, Eisenberg N, Wang Y. Predicting internalizing problems in Chinese children: The unique and interactive effects of parenting and child temperament. Development and Psychopathology. 2013; 25(3):653-67 [DOI:10.1017/S0954579413000084] [PMID] [PMCID]

[7] McDermott Panetta Sh, Somers CL, Ceresnie AR, Hillman SB, Partridge RT. Maternal and paternal parenting style patterns and adolescent emotional and behavioral outcomes. Marriage \& Family Review. 2014; 50(4):342-59. [DOI:10.1080/01494929.2013.879557]

[8] Branje SJ, Hale WW, Frijns T, Meeus WH. Longitudinal associations between perceived parent-child relationship quality and depressive symptoms in adolescence. Journal of Abnormal Child Psychology. 2010; 38(6):751-63. [DOI:10.1007/s10802-010-9401-6] [PMID] [PMCID]

[9] Smith DE, Moore TM. Parenting style and psychosocial outcomes in a sample of Jamaican adolescents. International Journal of Adolescence and Youth. 2013; 18(3):176-90. [DOI:10.1080/02673843. 2012.682593]

[10] Shariati S, Emami Pour S. [Parent-adolescent conflict as a mediator between perceived parenting styles and dimensions of anger expression (Persian)]. Quarterly Journal of Family and Research. 2015; 11(4):7-22. http://qjfr.ir/article-1-59-fa.html
[11] Neshatdoost HT. [Adolescents depression and individual and family related factors (Persian)]. Research Bulletin of Isfahan University (Humanities). 2002; 14(2):157-81. http://ensani.ir/fa/article/285098

[12] Aslani Kh, Varasteh M, Amanelahi A. [Effectiveness of positive parenting program training on parent-child interaction quality (Persian)]. Counseling Culture and Psycotherapy. 2017; 7(28):183-201. http://qccpc.atu.ac.ir/article_7095.html

[13] Tahmasian C, Jazayeri A R, Mohammadkhani P, Ghazi Tabatabaie $M$. [Modeling of physical self-efficacy in adolescence depression: Bandura's agentic model of depression (Persian)]. Archives of Rehabilitation. 2007; 8:34-9. http://rehabilitationj.uswr.ac.ir/article1-127-fa.htm

[14] Klahr AM, McGue M, lacono WG, Burt SA. The association between parent-child conflict and adolescent conduct problems over time: Results from a longitudinal adoption study. Journal of $A b-$ normal Psychology. 2011; 120(1):46-56. [DOI:10.1037/a0021350] [PMID] [PMCID]

[15] Hoskins DH. Consequences of parenting on adolescent outcomes. Societies. 2014; 4(3):506-31. [DOI:10.3390/soc4030506]

[16] Kovacs M. Children's Depression Inventory: A measure of depressive symptoms in children and adolescents. North Tonawanda: Maria Kovacs, Ph.D. and Multi-Health Systems Inc; 2001.

[17] Rajabi GR, Attari YA. [Factor analysis of children and adolescents depression inventory questionnaire (Persian)]. Journal of Counseling Research. 2004; 1(9-10):83-102. https://www.sid.ir/fa/jour nal/ViewPaper.aspx?id=9510

[18] Baumrind D. The influence of parenting style on adolescent competence and substance use. The Journal of Early Adolescence. 1991; 11(1):56-95. [DOI:10.1177/0272431691111004]

[19] Moradian J, Alipour S, Shehni Yailagh M. [The causal relationship between parenting styles and academic performance mediated by the role of academic self-efficacy and achievement motivation in the students (Persian)]. Journal of Family Psychology. 2014; 1(1):6374. http://ijfp.ir/article-1-55-en.html

[20] Prinz RJ, Foster S, Kent RN, O'Leary KD. Multivariate assessment of conflict in distressed and non-distressed mother adolescent dyads. Journal of Applied Behavior Analysis. 1979; 12(4):691-700. [DOI:10.1901/jaba.1979.12-691] [PMID] [PMCID]

[21] Fuligni AJ. Authority, autonomy, and parent-adolescent conflict and cohesion: A study of adolescents from Mexican, Chinese, Filipino, and European backgrounds. Developmental Psychology. 1998; 34(4):782-92. [DOI:10.1037/0012-1649.34.4.782] [PMID]

[22] Osorio A, González-Cámara M. Testing the alleged superiority of the indulgent parenting style among Spanish adolescents. Psicothema. 2016; 28(4):414-20. [DOI:10.7334/psicothema2015.314] [PMID]

[23] Sharma M, Sharma N, Yadava A. Parental styles and depression among adolescents. Journal of the Indian Academy of Applied Psychology. 2011; 37(1):60-8. https://psycnet.apa.org/record/2011-00205-006

[24] Sohrabzadeh Fard A, Gharraee B, Asgharnejad Farid AA, Aghebat A. [Relationship between perceived parenting styles and identity styles with intensity of depression in adolescents (Persian)]. Iranian Journal of Psychiatry and Clinical Psychology. 2017; 22(4):292-9. [DOI:10.18869/nirp.ijpcp.22.4.292] 
[25] Abolqasemi Sh, Nikdoost AA. [The relationship between perceived parenting styles and emotional intelligence and social adjustment in male students (Persian)]. Quarterly Journal of Social Work. 2015; 4(2):17-26. http://socialworkmag.ir/article-1-67-en.htm

[26] Arbete S. Parenting style as a predictor of internal and external behavioural symptoms in children: The child's perspective. Handledare/Supervisor Jimmy JensenExaminator/Examiner Peter Jönsson., 15 hp, förMagisterexamen i PsykologiVT 2016

[27] Newman K, Harrison L, Dashiff C, Davies S. Relationships between parenting styles and risk behaviors in adolescent health: An integrative literature review. Revista Latino-Americana de Enfermagem. 2008; 16(1):142-50. [DOI:10.1590/S0104-11692008000100022] [PMID]

[28] Laboviti B. Perceived parenting styles and their impact on depressive symptoms in adolescent 15-18 years old. Journal of Educational and Social Research. 2015; 5(1):171-6. [DOl:10.5901/jesr.2015. v5n1p171]

[29] Shalini A, Balakrishna Acharya YT. Perceived paternal parenting style on emotional intelligence of adolescents. Guru Journal of Behavioral and Social Sciences. 2013; 1(4):194-202. http://gjbss.org/ wp-content/uploads/2013/12/GJBSS-paper-3-Shalini+-balakrishna. pdf

[30] Bi X, Yang Y, Li H, Wang M, Zhang W, Deater-Deckard K. Parenting styles and parent-adolescent relationships: The mediating roles of behavioral autonomy and parental authority. Frontiers in Psychology. 2018; 9:2187. [DOI:10.3389/fpsyg.2018.02187] [PMID] [PMCID]

[31] Sorkhabi N, Middaugh E. How variations in parents' use of confrontive and coercive control relate to variations in parent-adolescent conflict, adolescent disclosure, and parental knowledge: Adolescents' perspective. Journal of Child and Family Studies. 2014; 23:1227-41. [DOI:10.1007/s10826-013-9783-5]

[32] You S, Lim SA. Development pathways from abusive parenting to delinquency: The mediating role of depression and aggression. Child Abuse \& Neglect. 2015; 46:152-62. [DOI:10.1016/j.chiabu.2015.05.009] [PMID] 